\title{
Alcohol abuse and glycoconjugate metabolism
}

\author{
Napoleon Waszkiewicz ${ }^{1}$, Sławomir Dariusz Szajda ${ }^{2}$, Anna Zalewska ${ }^{3}$, Agata Szulc ${ }^{1}$, \\ Alina Kępka ${ }^{4}$, Alina Minarowska ${ }^{5}$, Marzena Wojewódzka-Żelezniakowicz ${ }^{2}$, \\ Beata Konarzewska ${ }^{1}$, Sylwia Chojnowska ${ }^{6}$, Jerzy Robert Ladny ${ }^{2}$, Krzysztof Zwierz ${ }^{7}$ \\ ${ }^{1}$ Department of Psychiatry, Medical University of Bialystok, Poland \\ ${ }^{2}$ Department of Emergency Medicine and Disasters, Medical University of Bialystok, Poland \\ ${ }^{3}$ Department of Pedodontics, Medical University of Bialystok, Poland \\ ${ }^{4}$ Department of Biochemistry and Experimental Medicine, the Children's Memorial Health Institute, \\ Warsaw, Poland \\ ${ }^{5}$ Department of Anatomy, Medical University of Bialystok, Poland \\ ${ }^{6}$ Medical Institute, College of Computer Science and Business Administration, Lomza, Poland \\ ${ }^{7}$ Medical College of the Universal Education Society, Lomza, Poland
}

\begin{abstract}
The relationship between alcohol consumption and glycoconjugate metabolism is complex and multidimensional. This review summarizes the advances in basic and clinical research on the molecular and cellular events involved in the metabolic effects of alcohol on glycoconjugates (glycoproteins, glycolipids, and proteoglycans). We summarize the action of ethanol, acetaldehyde, reactive oxygen species (ROS), nonoxidative metabolite of alcohol - fatty acid ethyl esters (FAEEs), and the ethanol-water competition mechanism, on glycoconjugate biosynthesis, modification, transport and secretion, as well as on elimination and catabolism processes. As the majority of changes in the cellular metabolism of glycoconjugates are generally ascribed to alterations in synthesis, transport, glycosylation and secretion, the degradation and elimination processes, of which the former occurs also in extracellular matrix, seem to be underappreciated. The pathomechanisms are additionally complicated by the fact that the effect of alcohol intoxication on the glycoconjugate metabolism depends not only on the duration of ethanol exposure, but also demonstrates dose- and regional-sensitivity. Further research is needed to bridge the gap in transdisciplinary research and enhance our understanding of alcohol- and glycoconjugate-related diseases. (Folia Histochemica et Cytobiologica 2012, Vol. 50, No. 1, 1-11)
\end{abstract}

Key words: ethanol, alcohol, glycoconjugate, metabolism

\section{Introduction}

Roughly 2 billion people worldwide consume alcoholic beverages, and there are 76.3 million with diagnosable alcohol use disorders [1]. Consumed ethanol is metabolized by oxidative and nonoxidative pathways [2-4]. Three metabolic oxidative pathways of ethanol have been described so far. They involve

Correspondence address: N. Waszkiewicz,

Department of Psychiatry, Medical University of Bialystok,

Plac Brodowicza 1, 16-070 Choroszcz, Poland;

tel./fax: + 48857193977 ;

e-mail: napoleonwas@yahoo.com,napwas@wp.pl the following enzymes: alcohol dehydrogenase $(\mathrm{ADH})$, microsomal ethanol oxidizing system (MEOS), and catalase. The bulk of ingested ethanol is metabolized oxidatively by ADH in the stomach and liver, but oxidation in non-habitual alcohol consumers is carried out mostly by intra-hepatic $\mathrm{ADH}$ where alcohol is metabolized at its first pass $[5,6]$. Catalase is capable of oxidizing ethanol in the presence of a $\mathrm{H}_{2} \mathrm{O}_{2}$-generating system (mostly in vitro) and under physiological conditions appears not to play a major role. During ethanol metabolism, formed acetaldehyde is subsequently oxidized to acetate through the action of aldehyde dehydrogenase [5]. Chronic and high ethanol consumption results in a proliferation of the liver smooth endoplas- 


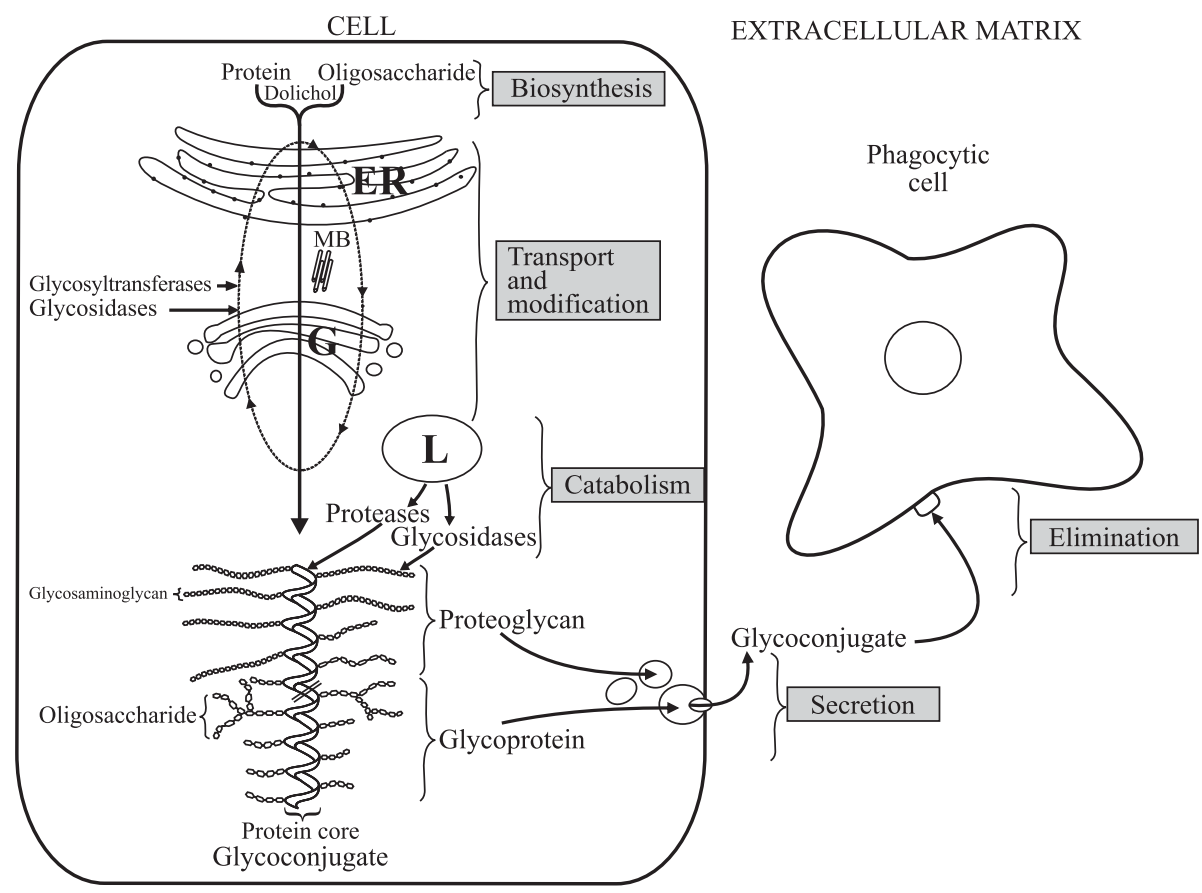

Figure 1. Steps of glycoconjugate metabolism. ER — endoplasmic reticulum; MB — microtubules; G — Golgi complex; $\mathrm{L}$ - lysosomes. Italic characters describe steps of metabolism

mic reticulum, inducing cytochrome P-4502E1 (CYP2E1), in particular through a rise in mRNA and posttranscriptional mechanism of tolerance involving stabilization against degradation [5]. The nonoxidative estrification pathways are able to metabolize no more than $0.1 \%$ of ethanol [7]. Fatty acid ethyl esters (FAEEs) are estrification products of ethanol and fatty acids or fatty acyl-CoA. This nonoxidative pathway is mediated by cytosolic and microsomal FAEE synthase and occurs mainly in the organs commonly damaged by alcohol (pancreas, liver, heart, and brain) [2].

Glycoproteins, glycolipids, and proteoglycans are referred to as glycoconjugates or complex carbohydrates. The biological roles of the oligosaccharide units of individual classes of glycoconjugates include: maintaining conformation and stability of proteins, being a target for receptors on microorganisms and the masking of such target structures, control of the half-life of conjugated proteins and cells, modulation of glycoconjugate functions, mediating of ligands binding, as well as cell-matrix and cell-cell interactions [8]. The metabolism of glycoconjugates involves several intricate metabolic steps including protein or ceramide synthesis, glycosylation, secretion, elimination and/or degradation (Figure 1). Glycosylation and subsequent steps of glycoconjugate metabolism require a glycosyl carrier and adequate precursor supplies, endomembrane transport and multiple glycosyltransferase and glycosidase systems, function of tubulin, receptors, and lysosomal complexes $[9,10]$.

As the bulk of ingested ethanol, and most serum glycoproteins, are metabolized in the liver, both metabolisms interfere with each other, resulting in glycoconjugate metabolic errors $[9,10]$.

\section{The mechanisms of ethanol action}

Ethanol, acetaldehyde, generated ROS, non-oxidative metabolites of ethanol (e.g. FAEEs), and the ethanol-water competition mechanism may all be involved in the toxic effects of alcohol on the metabolism of glycoconjugates [2-4, 11-19]. In particular, the highly reactive acetaldehyde is capable of forming adducts with amino groups (Schiff bases) and sulfhydryl groups of proteins (Figure 2), interfering with some of the glycoconjugate metabolic steps, e.g. decreasing activity of glycosyltransferases in rat brain and liver causes morphological changes of the Golgi complex and decreases the secretory process by inhibiting tubulin polymerization [9]. Induced CYP2E1 generates reactive oxygen species (ROS) such as superoxide radical and hydrogen peroxide (Figure 3). In the presence of iron, which increases during ethanol intoxication, more powerful oxidants such as hydroxyl radicals, ferryl species, and 1-hydroxyethyl radicals, are produced [20]. ROS can pro- 
A<smiles>[R][Y13](N)C1CCCC1[R]</smiles>
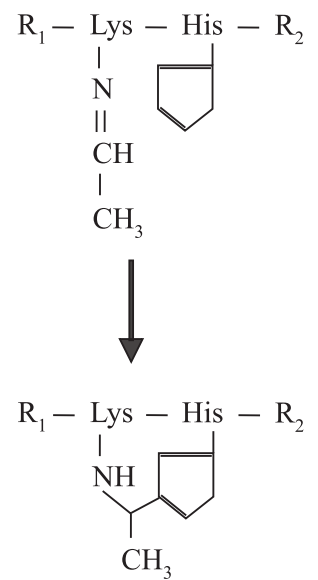

B

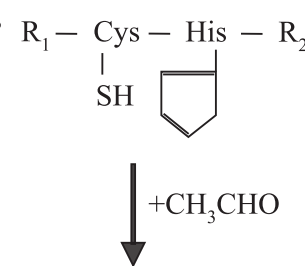

$\underset{\substack{\mathrm{C} \\ \mathrm{I}}}{\mathrm{R}_{1}-\mathrm{OH}} \underset{\mathrm{CH}}{\mathrm{C}}$
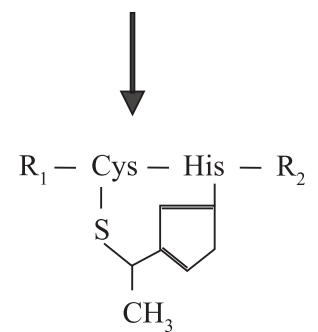

C

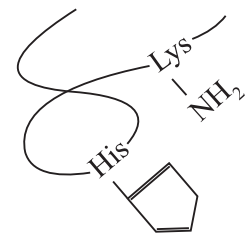<smiles>CCC=O</smiles>

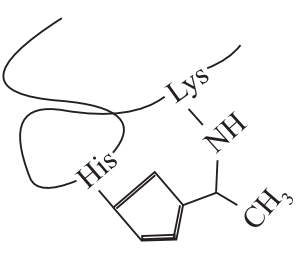

Figure 2. Modification of amino (A) and sulfhydryl (B) groups of amino acids by acetaldehyde. Protein adduct formation (C)

mote conformational changes of proteins by protein oxidation, they can inactivate enzymes, they can degrade proteoglycans, and they can cause oxidative damage to the DNA. The oxidative reductive depolymerization of hyaluronate (the constituent of proteoglycans) proceeds essentially by random destruction of unit monosaccharides due to oxygen-derived free radicals, followed by secondary hydrolytic cleavage of the resulting unstable glycosidic substituents [21]. ROS, via lipid peroxidation and the production of reactive lipid aldehydes such as malondialdehyde and 4-hydroxynonenal, which are diffusible molecules, can damage cellular membranes (Figure 3, Table 1) [20].

Ethanol oxidation to acetaldehyde and to acetic acid is accompanied by an excessive reduction of nicotinamide adenine dinucleotide (NAD), with a shift in the NADH/NAD ratio (Figure 4). Chronic ethanol consumption decreases activity of almost all mitochondrial complexes (excluding complex II) e.g. it decreases activity and heme content of cytochrome oxidase, decreases electron transport and proton translocation through complex I, decreases cytochrome b content in complex III, and reduces function in ATP synthase complex [22].

Thus, cell energy metabolism and ATP availability is markedly limited and, together with elevated $\mathrm{NADH} / \mathrm{NAD}$ ratio, it lowers carbohydrate and lipid metabolism and finally causes a decrease in gluco-

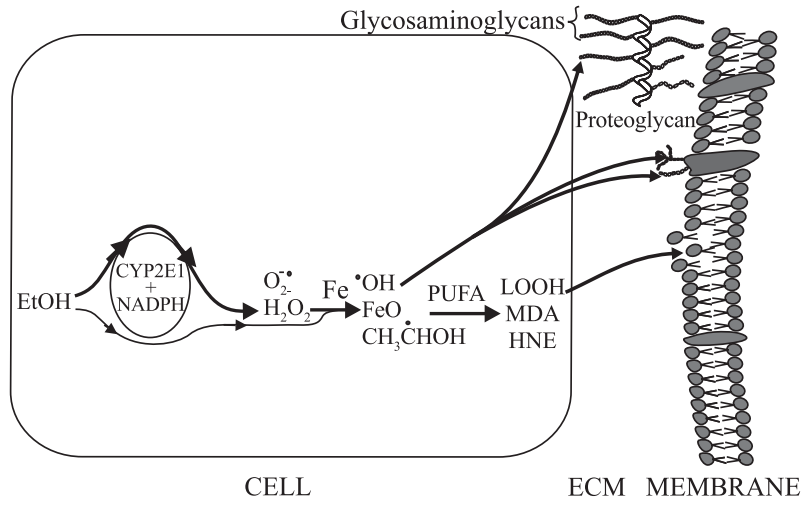

Figure 3. Ethanol-induced generation of reactive oxygen species and its toxicity to membranes and extracellular matrix. CYP2E1 - cytochrome P-4502E1; NADPH reduced nicotinamide adenine dinucleotide phosphate; ECM - extracellular matrix; $\mathrm{Fe}$ - iron; $\mathrm{O}_{2} \cdot{ }^{*}$ - superoxide radical; $\mathrm{H}_{2} \mathrm{O}_{2}-$ hydrogen peroxide; $\mathrm{OH}-$ hydroxyl radicals; $\mathrm{FeO}$ - ferryl species; $\mathrm{CH} 3 \mathrm{CHOH}-1$-hydroxyethyl radical; PUFA - polyunsaturated fatty acids; $\mathrm{LOOH}$ — reactive lipid aldehydes; MDA — malondialdehyde; HNE - 4-hydroxynonenal

neogenesis and the diversion of metabolism to ketogenesis and fatty acids synthesis $[3,4,19]$. Incorporated into membranes, FAEEs have been shown to cause uncoupling of oxidative phosphorylation in mitochondria and an increase in membrane fluidity 
Table 1. Mechanisms of ethanol-induced increase in membrane permeability

\begin{tabular}{|c|c|c|c|c|}
\hline Molecule/Metabolite & Mechanism & Effect & Consequence & Reference \\
\hline Ethanol & $\begin{array}{l}\text { Water displacement and hydrogen } \\
\text { bonds destroying, activation } \\
\text { of glycohydrolases (sialidase) }\end{array}$ & $\begin{array}{c}\text { Reduction in membrane surface } \\
\text { hydration and } \\
\text { liberation of functional groups }\end{array}$ & \multirow{4}{*}{$\begin{array}{l}\text { Impairments } \\
\text { in membrane } \\
\text { charge value } \\
\text { and } \\
\text { in membrane } \\
\text { stabilization }\end{array}$} & $\begin{array}{l}{[2]} \\
{[4]}\end{array}$ \\
\hline Acetaldehyde & $\begin{array}{l}\text { Modification of amino acid residues } \\
\text { of membrane proteins by reacting } \\
\text { with free amino and sulfhydryl groups }\end{array}$ & $\begin{array}{l}\text { Reduction in the positive charge } \\
\text { of proteins and lipids }\end{array}$ & & $\begin{array}{l}{[5]} \\
{[9]} \\
{[11]}\end{array}$ \\
\hline ROS & $\begin{array}{l}\text { Lipid peroxidation and lipid } \\
\text { hydroperoxide formation } \\
\text { Protein disruption }\end{array}$ & $\begin{array}{l}\text { Outer side exposure of } \\
\text { phosphatidylserine } \\
\text { Conformational changes }\end{array}$ & & $\begin{array}{l}{[12]} \\
{[16]}\end{array}$ \\
\hline $\mathrm{NAD}^{+} / \mathrm{NADH}$ ratio & Decrease in ATP synthesis & $\begin{array}{l}\text { Impairment in ion channel } \\
\text { functions }\left(\mathrm{Na}^{+}, \mathrm{K}^{+}, \mathrm{H}^{+}\right)\end{array}$ & & $\begin{array}{l}{[18]} \\
{[19]}\end{array}$ \\
\hline FAEE & $\begin{array}{l}\text { Formation of the esters of free } \\
\text { fatty acids with ethanol }\end{array}$ & $\begin{array}{l}\text { Changes in membrane } \\
\text { fluidity }\end{array}$ & $\begin{array}{l}\text { Decrease } \\
\text { in membrane } \\
\text { stability }\end{array}$ & $\begin{array}{l}{[23]} \\
{[24]}\end{array}$ \\
\hline
\end{tabular}

FAEE — fatty acid ethyl esters; $\mathrm{NAD}^{+},\left(\mathrm{NADH}, \mathrm{H}^{+}\right)$— nicotinamide adenine dinucleotide-oxidized (reduced) form; $\mathrm{ROS}$ — reactive oxygen species

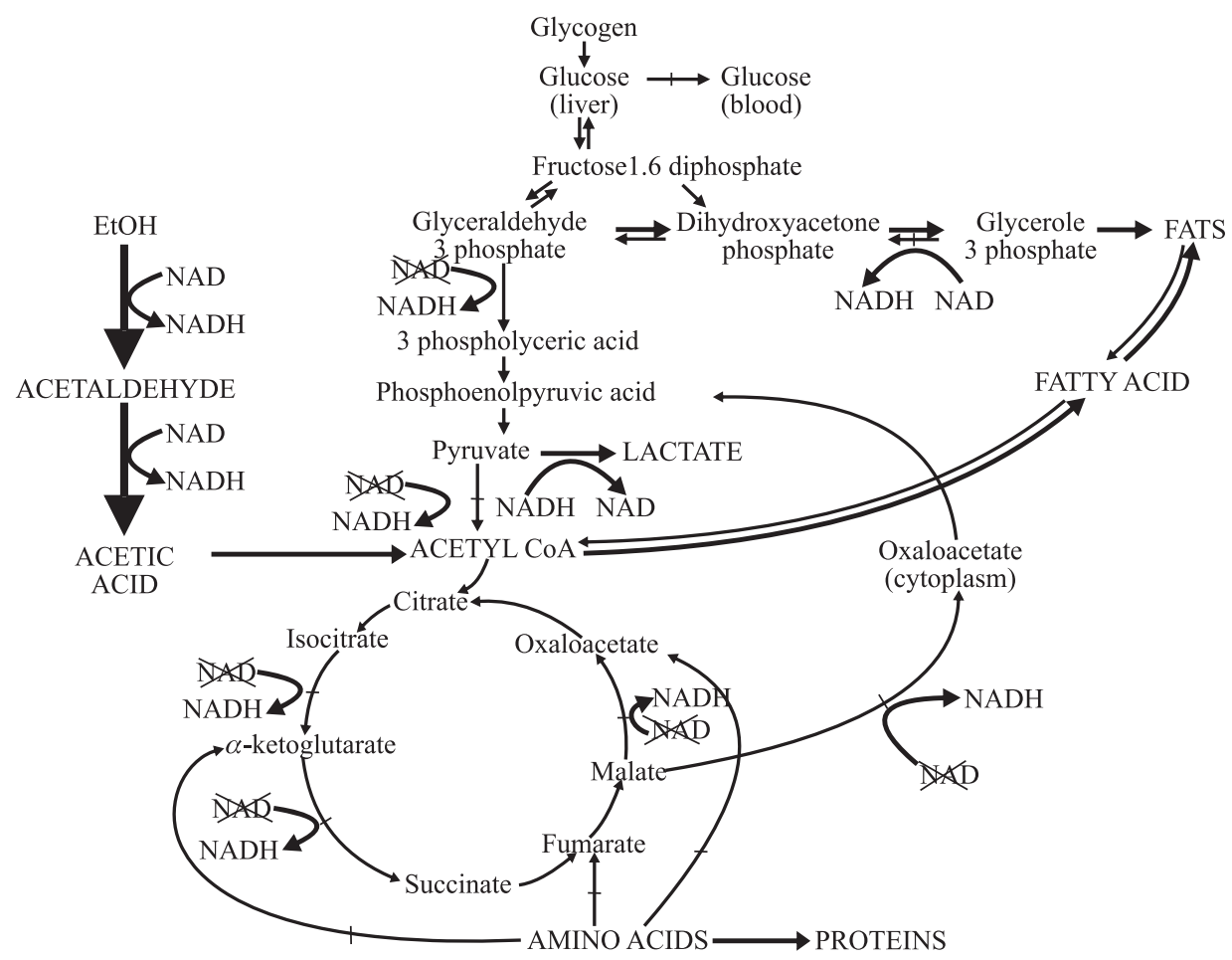

Figure 4. Mechanisms of ethanol-induced metabolic disturbances. NAD, (NADH) - nicotinamide adenine dinucleotideoxidized (reduced) form; - lack of NAD; $\rightarrow$ - inhibited pathway

$[2,23]$. Thus, disorder in the membrane bilayer and increase in the lysosomal fragility develop (Figure 5). Hydrolysis of FAEEs produces free fatty acids which are able to regulate molecular processes including the transcription process [2]. Membranes serve as a proximate site of alcohol action [24]. Ethanol and water compete with each other on target membrane molecules (Figure 6). Glycoproteins attract a large volume of water (up to $95 \%$ ). Thus displacement of water by ethanol from hydrogen-bonded sites creates the opportunity for allosteric changes that lead to conformational changes of membrane glycoconjugates [24].

All the abovementioned mechanisms are involved, directly or indirectly, in the destabilization of lysosomal and cellular membranes (Table 1). Therefore, the profound direct and indirect effect of alcohol on the function of membrane-bound macromolecules such as enzymes, ionic transport systems, surface recep- 


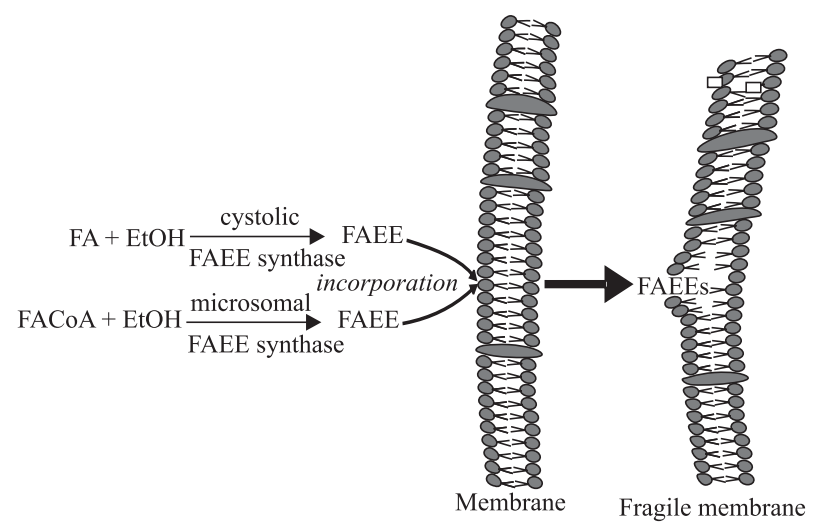

Figure 5. Synthesis and incorporation of fatty acid ethyl esters into membranes. FA - fatty acids; EtOH - ethanol; FAEEs - fatty acid ethyl esters; FACoA — fatty acid acyl-CoA

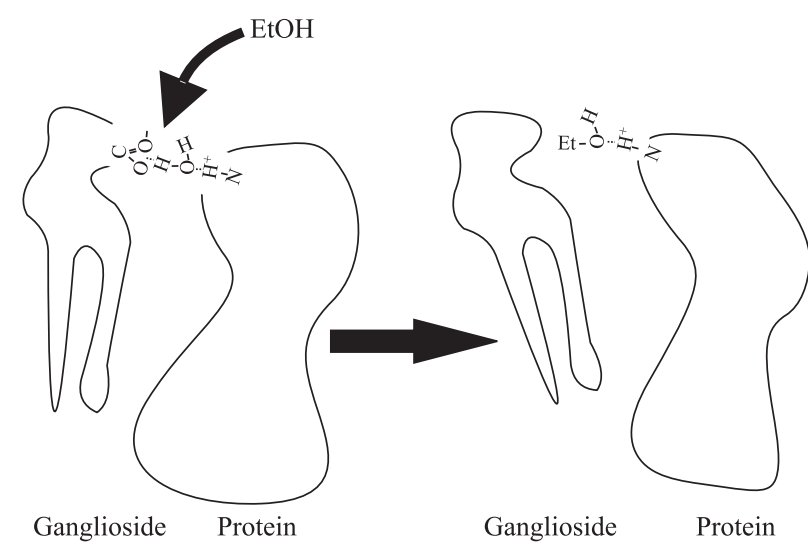

Figure 6. Mechanism of ethanol-water competition

tors, and second-messenger enzyme systems, may destroy an order in the physico-chemical microenvironment that is necessary for the proper interaction of membrane lipids, proteins and glycoconjugates [25].

\section{Glycoconjugate biosynthesis}

The glycan chains of glycoproteins are nearly always covalently linked to functional groups of amino acid side chains within a protein (GlcNAc $\beta 1$-Asn in N-glycans and GalNAc $\alpha 1$-Ser or -Thr in O-glycans) [26]. The protein moiety of glycoprotein is synthesized in rough endoplasmatic reticulum (Figure 1) [27]. During the translocation process from cytoplasm, through the aqueous pores of endoplasmic reticulum membrane (ER), to endoplasmatic reticulum, pre-propolypeptide chains undergo modifications including $\mathrm{N}$ - or O-glycosylation and folding assisted by chaperones [27]. The biosynthesis of glycans is a complex process that occurs along the secretory pathway [28].
The synthesis of asparagine-linked oligosaccharides of glycoproteins involves long-chain polyprenol dolichol which acts as a glycosyl carrier in the process of protein $\mathrm{N}$-glycosylation $[29,30]$. The synthesis of O-glycosidically linked saccharide chains requires individual nucleotide-activated monosaccharides added by site-specific glycosyltransferases in a stepwise manner [26]. Properly folded glycoproteins are transported along microtubules, due to vesicular transport by microtubule directed motor complex of dynein/dynactin or kinesin, to the pre-Golgi compartment. From this pre-Golgi compartment, glycoconjugete pass through the cis-, media-, and trans-Golgi network. During the intracellular transport, glycoconjugates are subjected to posttranslational modifications which include glycosidic and proteolytic processing, and the final phosphorylation [27]. Proteoglycans are conjugated of at least one covalently bound glycosaminoglycan chain, which may be heterogenous, attached to a protein core [26]. The biosynthetic pathway of glycosphingolipids follows the strategy used for O-glycans or glycosaminoglycans, where individual monosaccharides are added in a stepwise manner from nucleotide-activated precursors by specific glycosyltransferases [26].

Ethanol can inhibit both the early step of glycoprotein biosynthesis (dolichol-phosphate-dependent) at pre-Golgi process, and the terminal glycosylation and packaging (glycosyltransferase and free-dolicholdependent, respectively) at Golgi process [29]. Alcohol metabolism gives rise to the generation of excessive amounts of ROS [31, 32]. Dolichol has been found to be very sensitive to attack by free radicals [33], thus its function is easily declined during alcohol-induced oxidative stress. Acetaldehyde (the main metabolite of alcohol oxidation) has been reported to bind covalently to proteins of Golgi membranes (including to glycosyltransferases), decreasing terminal glycosylation at the level of the Golgi apparatus $[9,10,29,30]$. An increase in $\mathrm{NADH} / \mathrm{NAD}^{+}$ratio during drinking decreases ATP production by glycolytic pathway and citric acid cycle. Hence, the decrease in ATP availability may also limit synthesis of glycoconjugate [12]. Chronic exposure to ethanol has been shown to suppress the synthesis of DNA, RNA, and protein core [34]. The effects of ethanol depend on the tissue region (e.g. ethanol decreases protein synthesis in the cortex, cerebellum and brain stem, but not in the midbrain; the same dose of ethanol selectively decreases liver proteins in plasma, but does not affect extrahepatic proteins) and duration of exposure (e.g. the protein translation mechanism seems to be particularly susceptible to chronic ethanol exposure as compared to acute drinking) [35, 36]. 
Numerous reports have indicated that the main mechanism responsible for reduced protein synthesis is the formation of acetaldehyde-protein adducts with subcellular regulators of synthesis $[4,6,37,38]$. Ethanol reduces activation of translation initiation factors involved in the binding of met-tRNA to the 40S ribosomal subunit e.g. it reduces initiation factor $2 \mathrm{~B}$ (eIF2B) and the initiation factors involved in the binding of mRNA to the $43 \mathrm{~S}$ preinitiation complex eIF4E [13]. Chronic ethanol treatment has been shown to reduce the RNA content of muscles by $21 \%$, ribosome concentration by $22 \%$, and ribosome content by $39 \%$ [35]. However, there were no changes in the steady-state levels of ribosomal protein mRNA and 18S rRNA. This may suggest that either ribosome synthesis or breakdown was increased. Some studies have also implicated the generation of ROS and enhanced lipid peroxidation in the membrane damage that reduce amino acid transport that is necessary for protein core synthesis [13]. Endogenously generated FAEEs have been found to be the transcriptional regulators of nuclear hormone receptors of the peroxisome proliferator-activated receptor (PPAR) family [2]. Also, free fatty acids have been shown to act as transcriptional regulators in the PPAR family [2]. Incubation of pancreatic acinar cells with ethanol has been found to decrease protein synthesis by $20-30 \%$. The hydrolysis of FAEEs in these cells gave free fatty acids that were suggested to inhibit transcription.

\section{Modification, transport and secretion of glycoconjugates}

The balance between the action of glycosyltransferases and glycohydrolases (glycoconjugate synthesis and degradation balance) maintains the integrity of complex carbohydrates (Figure 1) [10,39]. After heavy alcohol drinking, an abnormal glycosylation of glycoproteins and glycolipids (due to decreased activity of glycosyltransferases including galactosyltransferase, sialyltransferase, $\mathrm{N}$-acetylglucosaminyltransferase, and increased activity of sialidase) and decreased secretion (due to inhibited polymerization of tubulin) of glycoproteins and glycolipids, have been reported [28, 40, 41]. Carbohydrate-deficient transferrin (CDT) has been widely investigated as one of the most valuable markers for monitoring chronic alcohol abuse $[9,10$, 30]. CDT is a mixture of the asialo, monosialo or disialo isoforms of transferrin, the $\mathrm{N}$-glycosylated protein. It appears in serum after regular high alcohol intake [9]. Similarly, the hepatic sialylation of apoprotein E (apoE), the O-glycosylated protein which is the component of plasma lipoprotein, has been decreased by chronic ethanol ingestion [42]. The inhibition of sialyltransferase and the induction of plasma sialidase (two enzymes involved in protein sialylation and desialylation respectively) have been considered to increase serum CDT and sialic acid-deficient apoE levels [10]. The destabilization of sialyltransferase (ST) mRNA by accelerating its degradation and the decrease in the hepatic synthetic rate of ST result in a concomitant decrease of steady-state level ST mRNA [4, 42].

It is very likely that increased presence of asialoconjugates and free sialic acid after alcohol exposure are promoted by increased transcription rates of cytosolic and plasma membrane sialidase mRNA (CS and PMS, respectively), whereas lysosomal sialidase and its mRNA are downregulated [43]. On the other hand, ethanol treatment inhibits activity of mannosidase II (most likely by acetaldehyde adduct formation), resulting in the synthesis of cell surface glycoproteins with high mannose structures [28]. The increase in the uptake of several monosaccharides depends on the type of monosaccharide, and on the cell type, as well as on the dose and the duration of alcohol consumption. Given that long-term ethanol exposure modulates the function of carbohydrate transporters located in the plasma membrane e.g. decreases uptake of glucose in astrocytes or increases in myotubes (decrease or increase in the levels of glucose transporter - GLUT), so a decrease in monosaccharide availability to glycosylation may also participate in inhibition of the glycosylation process [28].

Glycosylation of proteins is required for their proper folding, secretion, and stability [28, 44]. Thus, aforementioned ethanol-induced glycosylation disturbances (as increased deglycosylation), may impair folding of the glycoconjugates, their transport through the secretory pathway, and may contribute to a decrease in their life-span, subsequent distribution or subcellular localization [28, 44]. Exposure to ethanol, specifically to its metabolite acetaldehyde, causes morphological changes of the Golgi complex with an accompanying binding of the aldehyde to the proteins of the secretory fraction F1 which contains the highest amount of glycosyltransferases [29]. Acetaldehyde may impair the glycoprotein secretion process by inhibiting polymerization of tubulin [9]. Tuma et al. [11] have suggested that acetaldehyde can form adducts with the sulfhydryl groups of tubulin, the contractile protein necessary for secretion process. Diminished secretion could also be due to alcohol-induced alteration in glycoconjugate receptor, as a result of a decrease in its mRNA [45].

Alcohol exposure not only affects the microtubules' polymerization, but also affects actin filaments and reduces expression levels of the motor proteins kines- 
in and dynein, which play important roles in post-Golgi trafficking. Pre-Golgi transport (from endoplasmic reticulum to Golgi) may be affected by long-term alcohol exposure due to lowered exposure of regulators and effectors of GTPases (e.g. Rab, Rac) [45]. Different studies have described ethanol-induced impairments in exocytosis, endocytosis and nucleocytoplasmic transport that are involved in intracellular traffic of glycoconjugates $[45,46]$. Generally, two trafficking pathways are affected: transport of newly synthesized secretory or membrane glycoproteins from Golgi to the basolateral membrane, and clathrin-mediated endocytosis from the cell surface [46]. Both impaired secretion and internalization processes are associated with ethanol metabolism, being likely mediated by acetaldehyde.

\section{Catabolism of glycoconjugates}

It is known that alcohol impairs the function of almost all enzymatic cell systems [47, 48]. Lysosomal enzymes are involved in the catabolism of glycolipids, glycoproteins, and proteoglycans [19, 49]. The stabilization and improved biological resistance of glycoconjugates to proteolytic attack are due to the function of its carbohydrate side-chains [50]. Degradation of glycoproteins to monosaccharides and amino acids occurs by disassembly of the protein and oligosaccharides at the oligosaccharide-protein linkage region, with subsequent breakdown of proteins to amino acids and release of sugar monomers from nonreducing ends of oligosaccharide chains by the set of exoglycosidases [27, 51, 52]. It has even been proposed that deglycosylation of glycoconjugates may be a critical initial step leading to their subsequent proteolysis $[19,50,53]$. Various mechanisms are responsible for the alcohol-induced increase in the activity of lysosomal enzymes in extracellular space (including serum) e.g. increased lysosomal membrane permeability and leakage of the enzyme from lysosomes and subsequently from cells to the body fluids, delayed removal of the enzymes from the fluid, impaired glycosylation and subsequent trafficking of lysosomal hydrolases to organelles, enhanced synthesis of the enzyme by activated leucocytes, or leakage from damaged cells $[16,18,37,47$, 54-56]. During ethanol intoxication, the cellular and lysosomal membranes are impaired (Table 1), and proteases, together with glycosidases, may be translocated into the cytosol fraction, the intercellular space, and the body fluids, contributing to glycoconjugate catabolism [49, 51, 57, 58]. Acetaldehyde and reactive oxygen species, generated during alcohol intoxication, may modify proteins and lipids in the lysosomal and cellular membranes, increasing mem- brane fragility, thus releasing hydrolases to the cytosol and extracellular space (Figures 2, 3) [48, 51, 58]. The ethanol-induced displacement of membrane-bound water (Figure 6) and decrease in ATP synthesis during alcohol consumption may also participate in destabilization of cellular membranes [24, 58]. The nonoxidative pathway products of ethanol metabolism, fatty acid ethyl esters (FAEEs), formed by FAEE synthase, have been shown to produce changes in membrane fluidity (Figure 5), which has been shown to increase lysosomal fragility $[2,59]$. The extent of lysosomal membrane permeabilization determines the kind of cellular damage; from apoptosis in limited releasing of hydrolases, to necrosis and uncontrolled death in complete lysosomal membrane disruption [49].

Inadequately protected intestinal mucosal surface due to impaired glycoprotein synthesis and secretion [38] becomes considerably more permeable than normally protected mucosa for gut endotoxin (LPS-lipopolysaccharide) [60]. LPS binding to endotoxin receptor CD14, activates Kupffer cells to produce various mediators such as prostaglandin D2 and E2 (PGD2, PGE2), reactive nitrogen and oxygen species (RNS, ROS), endothelin-1 (ET-1), tumor necrosis factor- $\alpha$ (TNF- $\alpha$ ), and interleukin 1 and 6 (IL-1, IL-6) [61-63]. The 'swift increase in alcohol metabolism' (SIAM) is due mostly to the PGE2 production [60, 64]. Subsequent to hepatic hypermetabolic state (SIAM) hypoxia and ROS formation, may result in liver cell death and additional hydrolase releasing [60, 65]. An increased synthesis of lysosomal enzymes during reticuloendothelial cell activation may enhance degradation of linked oligosaccharides with subsequent tissue damage [56]. Damaged cells as well as the regeneration processes induced by ethanol metabolites (as those released by activated reticuloendothelial cells e.g. Kupffer cells), may be in turn the source of increased lysosomal enzyme activities in serum $[18,66,67]$. The decreased clearance of lysosomal enzymes from the blood has been proposed to be an explanation for an increase in their blood activity. However, a higher level of precursor forms with higher molecular weight than intracellularly localized enzyme forms, seems to be due to increased production and secretion, rather than to decreased elimination or leakage from damaged cells [54].

As most lysosomal enzymes are glycoproteins, which are carbohydrate moieties consisting of asparagine-linked complex and high-mannose oligosaccharides [68], we can speculate that the same mechanisms which are involved in decreased synthesis, modification, transport, clearance and degradation of glycoproteins during alcohol drinking, may also contrib- 
ute, in some degree, to the slow recovery in the activity of some of these lysosomal enzymes. The formation of ROS and acetaldehyde adducts makes conjugated proteins more susceptible to proteolysis [15]. ROS, separately, are capable of degrading some of the glycoconjugates [69]. ROS and hydroxyl radicals in particular have been demonstrated to be capable of the degradation of the major extracellular matrix components: collagen, proteoglycans and glycosaminoglycans (Figure 3 ).

Non-sulphated glycosaminoglycans (GAGs) such as hyaluronian and chondroitin are the most susceptible to ROS fragmentation. Moseley et al. [69] even proposed that lysosomal glycosidases, derived from polymorphonuclear leukocytes, exert no degradational effect upon intact degradation of glycoconjugates by ROS. This effect is thought to occur via the random modification to the unit monosaccharides, followed by the hydrolytic cleavage of the unstable constituents. Ethanol and water compete with each other on target membrane molecules, creating the opportunity for allosteric changes (Figure 6) [24]. Sialoglycoconjugates are normally poorly accessible to sialidase. Thus, displacing water, ethanol may lead to conformational changes of glycoconjugates, making them more accessible and vulnerable to enzymatic degradation $[24,39]$.

\section{Elimination of glycoconjugates}

The aging and the half-life of serum glycoconjugates depend on the loss of carbohydrate side-chains [4, 66]. Carbohydrate side-chains increase their elimination time by different carbohydrate-specific receptors and their subsequent lysosomal degradation [10]. The receptors for clearance of specifically terminated glycoproteins (e.g. galactose-, fucose-, or mannose- terminated) have been found on hepatocytes, phagocytic cells (e.g. on Kupffer cells), and on the hepatic endothelial cells [70]. Chronic ethanol administration has been shown to decrease the asialoglycoprotein receptor content in rat hepatocytes [71], which elevated levels of desialylated glycoproteins. It provided evidence for derangements in the carbohydrate recognition system in alcoholics [66]. Besides the tendency of activated reticuloendothelial cells to release lysosomal enzymes, these cells might contribute in part to their clearance upon activation [56].

\section{Dose-dependence and time of consumption-dependence}

A single high dose of ethanol $(2 \mathrm{~g} / \mathrm{kg})$ as well as chronic drinking decrease whole-brain total sialic acid (SA), lipid- and protein-bound SA [72, 73], increasing free SA in tissues including serum $[74,75]$. These changes may be ascribed to the active sialidase-mediated catabolic processes in acute and chronic drinking. A single ethanol dose of $0.55 \mathrm{~g} / \mathrm{kg}$ showed no effect on the content of gangliosidic SA in the brain [25], whereas doses of 1-2 $\mathrm{g} / \mathrm{kg}$ caused significant decrease in total brain SA; larger doses of 3-6 g/ $\mathrm{kg}$ were ineffective [74]. Stimulation of sialidase by $1-2 \mathrm{~g} / \mathrm{kg}$ dose of ethanol has been found to be the reason for reduced total SA, whereas ineffective larger doses of 3-6 g/ kg could have been inhibiting sialidase [24]. Acetaldehyde effect was excluded as a reason of degradative changes because SA levels were also reduced by t-butanol [24]. Desialylated or hyposialylated gangliosides are the source of the reduced sialic acid in lipids [24]. Although an acute dose of ethanol has been found to decrease total brain gangliosides (by up to $40 \%$ ) [76], surprisingly, no major effect of chronic drinking has been found on any of the ganglioside species [77]. According to total tissue SA levels, ganglioside decrement was observed at $1-2 \mathrm{~g} / \mathrm{kg}$ of single ethanol injection, but not at larger doses [25]. Thus, the reason why a larger dose does not induce gangliosides decline might also be the inhibiting effect of such a dose on the activity of catabolic enzymes (e.g. on sialidase). Tolerance to alcohol may be responsible for the lack of significant changes in gangliosides during repeated alcohol exposure (chronic drinking), which often is attributed to changes in membrane composition (e.g. in increased cholesterol content) that make it more difficult for ethanol to fluidize the membrane interior [24]. In acute alcohol intoxication, an enhanced catabolic process of proteins which constitute a core of glycoconjugates and a subsequent rise in ribosomal protein mRNAs may be a transient but significant response to induced metabolic stress [35]. In chronic intoxication, an unaltered steady-state level of the ribosomal protein mRNAs may suggest an adaptive response in which ribosomal protein mRNAs return to the level of controls, or may be ascribed to the aforementioned effect of membrane tolerance [35].

The different effects of chronic vs. acute ethanol exposure may depend also on cytokine production. For example, an acute ethanol exposure suppresses the LPS-induced clustering of Toll-like receptor (TLR4) and CD14, whereas chronic ethanol exposure exhibits a greater amount of expression of CD14, following LPS exposure [78]. LPS induces cytosolic phospholipase $\mathrm{A}_{2}$ activation (which is linked to mucin synthesis impairment) [79] and TNF- $\alpha 1$ protein production (which affects proteolysis) [80]. Therefore chronic ethanol exposure throughout LPS induced 
cytokine production impairs glycoconjugate synthesis to a higher degree than acute exposure. Also Ohtake et al. [81] reported an opposite metabolic effect of acute to chronic ethanol intoxication. A large single ethanol dose reduced rat liver synthesis of proalbumin by $53 \%$, whereas chronic exposure increased its levels up to 1.5 fold. Most salivary proteins are referred to as glycoproteins $[4,6,82]$. A significant decrease in salivary total (glyco)protein concentration, with an accompanying decrease in the activity of peroxidase and lysozyme concentration in acute ethanol intoxication, has been reported [6]. Chronic ethanol ingestion has been found to cause an increase in total salivary (glyco)protein concentration, with increased activity of peroxidase and lysozyme concentration [83]. The catabolic effect of ethanol on glycoconjugate is active in both acute and chronic intoxication as described on the basis of increased glycosidase activities (e.g. sialidase and $\beta$-hexosaminidase) $[18,24]$. However, less depressive effect of chronic intoxication on glycoconjugate (gangliosides, glycoproteins) content may depend on mechanisms of membrane tolerance, and on higher resistance of adapted metabolism to alcohol in which active catabolic processes may be compensated by increased glycoconjugate synthesis (increase in glycoconjugate turnover), as previously described by Cunningham et al. [35]. Glycoconjugate metabolism is also regionally differentiated. While chronic alcohol intake has been found to greatly reduce wholebrain sialic acid levels, a reduction in the medulla and in the forebrain did not develop [72]. In the cortex, cerebellum and brain stem, acute intoxication decreases protein synthesis, whereas the midbrain is not affected $[25,35,36]$.

\section{Concluding remarks}

The proposed mechanisms of alcohol-induced glycoconjugate metabolic errors are crucial in understanding the multifactorial pathogenesis of alcohol use disorders and alcohol related diseases.

The pathomechanisms are additionally complicated by the fact that the effect of alcohol intoxication on the glycoconjugate metabolism depends not only on the duration of ethanol exposure, but it is also doseand regionally-dependent.

Ethanol impairs the biosynthesis, transport, modification, as well as the elimination and catabolism of many diverse glycoconjugates. The precise mechanisms of all ethanol actions are yet not well understood. Among the glycoconjugate related diseases induced by ethanol exposure, fetal alcohol syndrome (FAS) and alcoholic liver disease (ALD) are the best characterized [84-89]. However, our understanding of the role of alcohol in these diseases, as well as in alcohol dependence syndrome, alcohol-associated carcinogenesis etc, is still to be improved.

It is considered that most changes in the glycoconjugate metabolism are due to alterations in their synthesis, transport, glycosylation and secretion [9, $38,39]$, but the elimination and degradational processes in particular have not yet been satisfactorily understood. Further research is needed to bridge the gap in transdisciplinary research to enhance our understanding of alcohol- and glycoconjugate-related diseases.

\section{References}

1. World Health Organization. Global Status Report on Alcohol. 2004 Geneva, Switzerland.

2. Laposata M. Fatty acid ethyl esters: ethanol metabolites which mediate ethanol-induced organ damage and serve as markers of ethanol intake. Prog Lipid Res. 1998;37:307-316.

3. Waszkiewicz N, Konarzewska B, Waszkiewicz M et al. Biomarkers of alcohol abuse. Part I. Traditional biomarkers and their interpretation. Psychiatr Pol. 2010;44:127-136.

4. Waszkiewicz N, Szajda SD, Kępka A, Szulc A, Zwierz K. Glycoconjugates in the detection of alcohol abuse. Biochem Soc Trans. 2011;39:365-369.

5. Lieber CS. Pathogenesis and treatment of alcoholic liver disease: progress over the last 50 years. Rocz Akad Med Bialymst. 2005;50:7-20.

6. Waszkiewicz N, Szajda SD, Jankowska A et al. The effect of acute ethanol intoxication on salivary proteins of innate and adaptive immunity. Alcohol Clin Exp Res. 2008;32:652-656.

7. Waszkiewicz N, Poplawska R, Konarzewska B et al. Biomarkers of alcohol abuse. Part II. New biomarkers and their interpretation. Psychiatr Pol. 2010;44:137-146.

8. Varki A. Biological roles of oligosaccharides: all of the theories are correct. Glycobiology. 1993;3:97-130.

9. Stibler H. Carbohydrate-deficient transferrin in serum: a new marker of potentially harmful alcohol consumption reviewed. Clin Chem. 1991;37:2029-2037.

10. Sillanaukee P, Strid N, Allen JP, Litten RZ. Possible reasons why heavy drinking increases carbohydrate-deficient transferrin. Alcohol Clin Exp Res. 2001;25:34-40.

11. Tuma DJ, Jennett RB, Sorrell MF. The interaction of acetaldehyde with tubulin. Ann NY Acad Sci. 1987;492:277-286.

12. Volpi E, Lucidi P, Cruciani $G$ et al. Moderate and large doses of ethanol differentially affect hepatic protein metabolism in humans. J Nutr. 1998;128:198-203.

13. Reilly ME, Patel VB, Peters TJ, Preedy VR. In vivo rates of skeletal muscle protein synthesis in rats are decreased by acute ethanol treatment but are not ameliorated by supplemental alpha-tocopherol. J Nutr. 2000;130:3045-3049.

14. Enberg N, Alho H, Loimaranta V, Lenander-Lumikari M. Saliva flow rate, amylase activity, and protein and electrolyte concentrations in saliva after acute alcohol consumption. Oral Surg Oral Med Oral Pathol Oral Radiol Endod. 2001;92: 292-298.

15. Patel VB, Worrall S, Emery PW, Preedy VR. Protein adduct species in muscle and liver of rats following acute ethanol administration. Alcohol Alcohol. 2005;40:485-493.

16. Waszkiewicz N, Szajda SD, Zalewska A et al. Binge drinking-induced liver injury. Hepatology. 2009;50:1676. 
17. Waszkiewicz N, Szajda SD, Konarzewska B, Szulc A, Kepka A, Zwierz K. Underappreciated role of binge drinking in the risk of lung cancer. Eur J Public Health. 2010;20:6.

18. Waszkiewicz N, Szajda SD, Jankowska A et al. The effect of the binge drinking session on the activity of salivary, serum and urinary $\beta$-hexosaminidase: preliminary data. Alcohol $\mathrm{Al}$ cohol. 2008;43:446-450.

19. Waszkiewicz N, Szajda SD, Jankowska A et al. Catabolism of salivary glycoconjugates in acute ethanol intoxication. Med Sci Monit. 2009;15:CR413-CR417.

20. Jaeschke H, Gores GJ, Cederbaum AI, Hinson JA, Pessayre D, Lemasters JJ. Mechanisms of hepatotoxicity. Toxicol Sci. 2002;65:166-176.

21. Uchiyama H, Dobashi Y, Ohkouchi K, Nagasawa K. Chemical change involved in the oxidative reductive depolymerization of hyaluronic acid. J Biol Chem. 1990;265:7753-7759.

22. Gramenzi A, Caputo F, Biselli M et al. Review article: alcoholic liver disease - pathophysiological aspects and risk factors. Aliment Pharmacol Ther. 2006;24:1151-1161.

23. Haber PS, Wilson JS, Apte MV, Pirola RC. Fatty acid ethyl esters increase rat pancreatic lysosomal fragility. J Lab Clin Med. 1992;121:759-764.

24. Klemm WR. Biological water and its role in the effects of alcohol. Alcohol. 1998;15:249-267.

25. Klemm WR. Membrane glycoconjugates as potential mediators of alcohol effects. Prog Neuropsychopharmacol Biol Psychiatry. 1987;11:633-658.

26. Reuter G, Gabius HJ. Eukaryotic glycosylation: whim of nature or multipurpose tool? Cell Mol Life Sci. 1999;55:368-422.

27. Zwierz K, Zalewska A, Zoch-Zwierz A. Isoenzymes of N-acetylbeta-hexosaminidase. Acta Biochim Pol. 1999;46:739-751.

28. Tomas M, Fornas E, Megias Let al. Ethanol impairs monosaccharide uptake and glycosylation in cultured rat astrocytes. J Neurochem. 2002;83:601-612.

29. Cottalasso D, Gazzo P, Dapino D et al. Effect of chronic ethanol consumption on glycosylation processes in rat liver microsomes and golgi apparatus. Alcohol Alcohol. 1996;31:51-59.

30. Flahaut C, Michalski JC, Danel T, Humbert MH, Klein A. The effects of ethanol on the glycosylation of human transferrin. Glycobiology. 2003;13:191-198.

31. Bautista AP. The role of Kupffer cells and reactive oxygen species in hepatic injury during acute and chronic alcohol intoxication. Alcohol Clin Exp Res. 1998;22:255S-259S.

32. Scott RB, Reddy KS, Husain K, SchlorffEC, Rybak LP, SomaniSM. Dose response of ethanol on antioxidant defense system of liver, lung, and kidney in rat. Pathophysiology. 2000;7:25-32.

33. Pronzato MA, Cottalasso D, Domenicotti C et al. Effects of $\mathrm{CCl}_{4}$ poisoning on metabolism of dolichol in rat liver microsomes and Golgi apparatus. Free Radic Res Commun. 1990;11:267-277.

34. Braza-Boils A, Tomas M, Marin MP et al. Glycosylation is altered by ethanol in rat hippocampal cultured neurons. $\mathrm{Al}$ cohol Alcohol. 2006;41:494-504.

35. Cunningham CC, Preedy VR, Palace AG et al. Ethanol and protein metabolism. Alcohol Clin Exp Res. 2001;25:262S-268S.

36. Bonner AB, Dalwai S, Marway JS, Preedy VR. Acute exposure to the nutritional toxin alcohol reduces brain protein synthesis in vivo. Metabolism. 2003;52:389-396.

37. Kharbanda KK, McVicker DL, Zetterman RK, Donohue TMJr. Ethanol consumption alters trafficking of lysosomal enzymes and affects the processing of procathepsin $\mathrm{L}$ in rat liver. Biochim Biophys Acta. 1996;1291:45-52.

38. Slomiany A, Morita M, Sano S, Piotrowski J, Skrodzka D, Slomiany BL. Effect of ethanol on gastric mucus glycoprotein synthesis, translocation, transport, glycosylation, and secretion. Alcohol Clin Exp Res. 1997;21:417-423.
39. Lands WE. Do alcohol and complex carbohydrates mix? Glycobiology. 1993;3:415-416.

40. Yamauchi M, Kimura K, Maezawa Y et al. Urinary level of L-fucose as a marker of alcoholic liver disease. Alcohol Clin Exp Res. 1993;17:268-271.

41. Tomas M, Marin P, Megias L, Egea G, Renau-Piqueras J. Ethanol perturbs the secretory pathway in astrocytes. Neurobiol Dis. 2005;20:773-784.

42. Lakshman MR, Rao MN, Marmillot P. Alcohol and molecular regulation of protein glycosylation and function. Alcohol. 1999;19:239-247.

43. Garige M, Azuine MA, Lakshman MR. Chronic ethanol consumption upregulates the cytosolic and plasma membrane sialidase genes, but down regulates lysosomal membrane sialidase gene in rat liver. Metabolism. 2006;55:803-810.

44. Ghosh P, Liu QH, Lakshman MR. Long-term ethanol exposure impairs glycosylation of both $\mathrm{N}$ - and O-glycosylated proteins in rat liver. Metabolism. 1995;44:890-898.

45. Esteban-Pretel G, María MP, Romero AM et al. Protein traffic is an intracellular target in alcohol toxicity. Pharmaceuticals. 2011;4;741-757.

46. Shepard BD, Fernandez DJ, Tuma PL. Alcohol consumption impairs hepatic protein trafficking: mechanisms and consequences. Genes Nutr. 2010;5:129-140.

47. Hultberg B, Isaksson A, Tiderstrom G. Beta-hexosaminidase, leucine aminopeptidase, cystidyl aminopeptidase, hepatic enzymes and bilirubin in serum of chronic alcoholics with acute ethanol intoxication. Clin Chim Acta. 1980;105:317-323.

48. Witek B, Kolataj A. Effect of ethanol administration on activities of some lysosomal hydrolases in the mouse. Gen Pharmacol. 1999;32:163-168.

49. Winchester B. Lysosomal metabolism of glycoproteins. Glycobiology. 2005;15:1R-15R.

50. Aronson NN Jr, Kuranda MJ. Lysosomal degradation of Asn-linked glycoproteins. Faseb J. 1989;3:2615-2622.

51. Knas M, Karaszewska K, Szajda SD, Zarzycki W, Dudzik D, Zwierz K. Saliva of patients with Type 1 diabetes: effect of smoking on activity of lysosomal exoglycosidases. Oral Dis. 2006;12:278-282.

52. Zalewska A, Brzoska MM, Marciniak J, Karaszewska K, Zwierz K, Moniuszko-Jakoniuk J. Activity of lysosomal exoglycosidases in submandibular glands of rats intoxicated by cadmium at doses related to human chronic environmental and occupational exposures. Acta Biochim Pol. 2004;51:831-837.

53. Sterer N, Greenstein RB, Rosenberg M. Beta-galactosidase activity in saliva is associated with oral malodor. J Dent Res. 2002;81:182-185.

54. Hultberg B, Isaksson A, Berglund M, Alling C. Increases and time-course variations in beta-hexosaminidase isoenzyme $\mathrm{B}$ and carbohydrate-deficient transferrin in serum from alcoholics are similar. Alcohol Clin Exp Res. 1995;19:452-456.

55. Karkkainen P. Serum and urinary beta-hexosaminidase as markers of heavy drinking. Alcohol Alcohol. 1990;25:365-369.

56. Wehr H, Czartoryska B, Gorska D, Matsumoto H. Serum beta-hexosaminidase and alpha-mannosidase activities as markers of alcohol abuse. Alcohol Clin Exp Res. 1991;15:13-15.

57. Dobrzynska I, Skrzydlewska E, Figaszewski Z. Parameters characterizing acid-base equilibria between cell membrane and solution and their application to monitoring the effect of various factors on the membrane. Bioelectrochemistry. 2006;69:142-147.

58. Skrzydlewska E, Roszkowska A, Moniuszko-Jakoniuk J. A comparison of methanol and ethanol effects on the activity and distribution of lysosomal proteases. Pol J Environ Stud. 1999;8:251-257. 
59. Dobryniewski J, Szajda SD, Waszkiewicz N, Zwierz K. Biology of essential fatty acids (EFA). Przegl Lek. 2007;64:91-99.

60. Thurman RG. II. Alcoholic liver injury involves activation of Kupffer cells by endotoxin. Am J Physiol. 1998;275:G605-G611.

61. Lands WE. Cellular signals in alcohol-induced liver injury: a review. Alcohol Clin Exp Res. 1995;19:928-938.

62. Hoek JB, Pastorino JG. Ethanol, oxidative stress, and cytokine-induced liver cell injury. Alcohol. 2002;27:63-68.

63. Zima T, Fialova L, Mestek O et al. Oxidative stress, metabolism of ethanol and alcohol-related diseases. J Biomed Sci. 2001;8:59-70.

64. Bradford BU, Enomoto N, Ikejima K et al. Peroxisomes are involved in the swift increase in alcohol metabolism. J Pharmacol Exp Ther. 1999;288:254-259.

65. Kurose I, Higuchi H, Miura S et al. Oxidative stress-mediated apoptosis of hepatocytes exposed to acute ethanol intoxication. Hepatology. 1997;25:368-378.

66. Hultberg B, Isaksson A, Berglund M, Moberg AL. Serum beta-hexosaminidase isoenzyme: a sensitive marker for alcohol abuse. Alcohol Clin Exp Res. 1991;15:549-552.

67. Albandar JM, Kingman A, Lamster IB. Crevicular fluid level of beta-glucuronidase in relation to clinical periodontal parameters and putative periodontal pathogens in early-onset periodontitis. J Clin Periodontol. 1998; 25:630-639.

68. Hasilik A, Von Figura K. Oligosaccharides in lysosomal enzymes. Distribution of high-mannose and complex oligosaccharides in cathepsin D and beta-hexosaminidase. Eur J Biochem. 1981;121:125-129.

69. Moseley R, Waddington RJ, Embery G. Degradation of glycosaminoglycans by reactive oxygen species derived from stimulated polymorphonuclear leucocytes. Biochim Biophys Acta. 1997;1362:221-231.

70. Fadden AJ, Holt OJ, Drickamer K. Molecular characterization of the rat Kupffer cell glycoprotein receptor. Glycobiology. 2003;13:529-537.

71. Casey CA, Kragskow SL, Sorrell MF, Tuma DJ. Effect of chronic ethanol administration on total asialoglycoprotein receptor content and intracellular processing of asialoorosomucoid in isolated rat hepatocytes. Biochim Biophys Acta. 1990;1052:1-8.

72. Klemm WR, Engen RL. Acutely administered ethanol decreases whole-brain sialic acid and cerebellar 2-deoxyribose. J Neurosci Res. 1979;4:371-382.

73. Klemm WR, Engen RL. Effects of ethanol on brain sialic acid and 2-deoxyribose in young rats. $J$ Stud Alcohol. 1979;40:554-561.

74. Klemm WR, Mathew J, Maring RG. Acute alcohol decreases gangliosides in mouse brain. Alcohol. 1988;5:215-219.
75. Sillanaukee P,Ponnio M,Seppa K. Sialic acid: new potential marker of alcohol abuse. Alcohol Clin Exp Res. 1999;23:1039-1043.

76. Klemm WR, Foster DM. Alcohol, in a single pharmacological dose, decreases brain gangliosides. Life Sci. 1986;39: 897-902.

77. Klemm WR, Foster DM. Effects of chronic alcohol consumption in weanling rats on brain gangliosides. Prog Neuropsychopharmacol Biol Psychiatry. 1986;10:697-702.

78. Dai Q, Pruett SB. Different effects of acute and chronic ethanol on LPS-induced cytokine production and TLR4 receptor behavior in mouse peritoneal macrophages. J Immunotoxicol. 2006;3:217-225.

79. Slomiany BL, Slomiany A. Leptin modulates the detrimental effect of Porphyromonas gingivalis lipopolysaccharide-induced cytosolic phospholipase A2 activation on salivary mucin synthesis via ERK-signal transduction. Inflammopharmacology. 2006;14:250-255.

80. Koll M, Ahmed S, Mantle D et al. Effect of acute and chronic alcohol treatment and their superimposition on lysosomal, cytoplasmic, and proteosomal protease activities in rat skeletal muscle in vivo. Metabolism. 2002;51:97-104.

81. Ohtake H, Kato S, Murawaki Y, Kishimoto Y, Wakushima T, Hirayama C. Acute and chronic effect of ethanol on hepatic albumin synthesis in rat liver in vitro. Res Commun Chem Pathol Pharmacol. 1986;53:213-231.

82. Waszkiewicz N, Zalewska A, Szulc A et al. The influence of alcohol on the oral cavity, salivary glands and saliva. Pol Merkur Lekarski. 2011;30:69-74.

83. Waszkiewicz N. The effect of acute and chronic ethanol intoxication on the salivary proteins of innate and adaptive immunity. PhD Thesis. 2010.

84. Waszkiewicz N, Szulc A. Diagnosis of alcohol abuse. Przegl Lek. 2009;66:529-534.

85. Mansouri A, Demeilliers C, Amsellem S, Pessayre D, Fromenty B. Acute ethanol administration oxidatively damages and depletes mitochondrial DNA in mouse liver, brain, heart, and skeletal muscles: protective effects of antioxidants.J Pharmacol Exp Ther. 2001;298:737-743.

86. Waszkiewicz N, Szulc A. Can we better prevent binge drinking? J Epidemiol Community Health. 2009;63:589.

87. Lieber CS. Hepatic, metabolic and toxic effects of ethanol: 1991 update. Alcohol Clin Exp Res. 1991;15:573-592.

88. Pshezhetsky AV, Ashmarina M. Lysosomal multienzyme complex: biochemistry, genetics, and molecular pathophysiology. Prog Nucleic Acid Res Mol Biol. 2001;69:81-114.

89. Stibler H, Sydow O. Carbohydrate composition of erythrocyte membranes and glycosidase activities in serum in patients with myotonic dystrophy, limb-girdle dystrophy and congenital myotonia. J Neurol Sci. 1984;63:285-298.

Submitted: 1 October, 2011 Accepted after reviews: 23 November, 2011 